\title{
Assessing the ecological hydrology of natural flow conditions in Taiwan
}

\author{
Fi-John Chang ${ }^{a, *}$, Meng-Jung Tsai ${ }^{a}$, Wen-Ping Tsai ${ }^{a}$, Edwin E. Herricks ${ }^{b}$ \\ a Department of Bioenvironmental Systems Engineering, National Taiwan University, No. 1, Section 4, Roosevelt Road, \\ Taipei 106, Taiwan \\ b Department of Civil and Environmental Engineering, University of Illinois at Urbana-Champaign, Urbana, USA
}

Received 15 June 2007; received in revised form 19 February 2008; accepted 25 February 2008

\section{KEYWORDS \\ Ecohydrology; \\ Ecohydrologic indica- \\ tors; \\ Natural flow regime; \\ River restoration; \\ Hydrological statistics; \\ Information redundancy}

\begin{abstract}
Summary There is a growing use of hydrologic indicators to describe the flow needs for organisms in riverine ecosystems. These indicators use hydrologic statistics as a foundation to understand flow variability and how this variability is related to the response of riverine ecosystems to natural and altered flow regimes. The Taiwan ecohydrology indicator system (TEIS) was developed to identify hydrologic statistics most appropriate to Taiwan fisheries. We provide a rigorous evaluation of hydrologic statistics used in the TEIS for 52 long-term flow records from 23 undisturbed watersheds in Taiwan. We have used the TEIS indicators for general flow, flow duration, and flow frequency to assess the natural flow regime conditions in these target watersheds. The correlation coefficients between TEIS statistics and physiological variables (area and elevation) for the target watersheds were also calculated. The expected high correlations between watershed area and flow related statistics were found. Elevation was correlated with frequency statistics. Cluster analysis was used to characterize relationships among TEIS statistics in the target watersheds and then group watersheds with similar characteristics. Both $\mathrm{K}$-mean and SOM clustering methods categorized the watershed statistics into three clusters and supported the assessment of potential redundancy in the hydrologic statistics. Although this analysis identified a high level of information redundancy in hydrological statistics, the actual information redundancy was reduced through the consideration of species life history and ecological requirements because these requirements demand calculation of all statistics that define habitat needs. This analysis supports the use of advanced cluster analysis techniques to supplement the analysis of hydrologic statistics, and uses station grouping and ecological interpretations to evaluate the natural flow regimes in Taiwan.

(c) 2008 Elsevier B.V. All rights reserved.
\end{abstract}

\footnotetext{
* Corresponding author. Tel.: +8862 23639461; fax: +886223635854.

E-mail address: changfj@ntu.edu.tw (F.-J. Chang).
} 


\section{Introduction}

Hydrology is recognized as a critical factor in the geomorphology and ecology of streams and rivers (Karr, 1981; Gordon et al., 2004). Hydrologic events are known to form and maintain channel planform and substrate while interactions among flow and channel structures create habitat for aquatic organisms. The understanding of the relationships between the flow regime characteristics of a river and its ecological functioning is crucial to the developing science of ecohydrology (Hughes and Hannart, 2003). This recognized connection between flow and organisms has resulted in the use of hydrologic statistics to characterize the physical conditions for organisms and to identify the natural flow regimes that are expected to enhance native fauna and provide a reasonable target for flow management. An emphasis on the flow management has encouraged the development of hydrologic indicators for the natural flow regimes (Olden and Poff, 2003), and a number of hydrologic statistics have been proposed for use as hydrologic indicators for river restoration and water resources management (Hughes and James, 1989; Poff, 1996; Richter et al., 1996, 1997; Clausen and Biggs, 2000). Olden and Poff (2003) reviewed 171 currently available hydrologic indicators and provided a statistically based framework used in selecting non-redundant hydrologic indices to describe the natural flow conditions. Their efforts focused on monitoring locations in the United States and were intended to identify indices that would explain the statistical variation in hydrologic indices and to minimize multicollinearity while adequately representing the flow regime. They also had a goal to assess the transferability of hydrologic indices and identify indices that explain the dominant patterns of variance.

Although the hydrologic basis for developing indicators is well defined by common techniques in stochastic hydrology (Chow et al., 1988), the selection of hydrological statistics for ecohydrological analysis is still the subject of discussion and research. The most common basis for the selection of ecohydrologic indicators is the identification of natural flow conditions, assuming that natural flows will benefit native species and more natural communities (Landres et al., 1999; Richter et al., 2003; Allan, 2004). Natural flow is a useful target because natural flows can be expected to reproduce habitat conditions that lead to sustaining endemic fauna and to support the restoration of ecosystems present before a disturbance if native organisms are still present to colonize a restored river. Critical requirements for the natural flow regime determination include a historical record from periods when hydrology was undisturbed by development, or the availability of undeveloped watersheds that can be used as references for the natural flow determination. In an ecohydrology analysis a "natural flow regime" is a continuing sequence of flows that meet ecosystem requirements for (1) the seasonal pattern of flows, (2) the Julian date or timing of extreme events, (3) the frequency and the duration of floods and droughts, (4) the seasonal and annual flow variability, and (5) the expected rate of change in natural flows (Poff et al., 1997). Ecohydrologic indicators are thus intended to quantify specific values for magnitude, frequency, duration, rate of change, and timing of flow conditions, which play important roles in sustaining or restoring the ecological integrity of flowing water systems.
The translation of hydrological statistics to ecohydrologic indicators is a continuing challenge to ecohydrology. Limited historical records and the absence of undeveloped comparison watersheds often compromise the natural flow regime analyses, and the ecological requirements of native fauna are incompletely understood. Further, methods to relate hydrologic statistics to species or aquatic community condition are still being developed (Herricks and Suen, 2006). There is a continuing need to develop flow regime requirements from the needs of organisms. One approach suggested is setting flow targets based on an autecological analysis of the existing, or desired, aquatic community and translation of those targets into ecohydrologic indicators (Suen and Herricks, 2006). It is the use of ecohydrologic indicators based on organism requirements coupled with a detailed analysis of hydrological statistics supporting those indicators that is the focus of this paper. The Taiwan ecohydrologic indicator system (TEIS) was developed by Suen (2005) using hydrologic statistics selected to meet species specific flow requirements. The TEIS used hydrologic statistics identified by Olden and Poff (2003) and the indicators of hydrologic alteration identified by Richter et al. (1996) with the environmental requirements of Taiwan freshwater fish species that was Suen and Herricks (2006). At issue is how hydrologic statistics used in the TEIS indicators can provide a useful addition to the existing ecohydrologic analysis. In particular, a demonstration is needed that relates TEIS statistics to a better understanding of flow pattern, timing, frequency, and variability that are tied to aquatic community needs. Further, it is known that the actual values of hydrologic statistics can vary over a relatively small land area that is characterized by topographic and climatic differences, which effect discharge and concentration time. Taiwan provides the ideal location to address whether this variability influences the interpretation of regional or local ecohydrological conditions. In addition, the calculation of hydrological statistics has brought the recognition that there is a potential for redundancy in the information provided by decision makers. It should be possible to reduce the number of measures and still provide an accurate characterization of flow regimes with a reduced set of hydrologic statistics that are more easily understood by watershed managers.

The focus of our analysis is Taiwan, an island in the Pacific Ocean. Taiwan presents an ideal opportunity to evaluate hydrological statistics for the local and regional analysis of ecohydrologic indicators. Taiwan's land area is approximately $36,000 \mathrm{~km}^{2}$ with mountains reaching $3952 \mathrm{~m}$. In this relatively small area, hydrologic monitoring has been conducted for over 50 years, providing a rich resource of hydrologic data from a dense network of gauging stations. Existing management divides Taiwan into regions and it has been possible to select watersheds that are relatively undisturbed for the natural flow regime analysis.

The objective of this research is to use advanced analysis procedures, specifically modern clustering techniques, to assess the hydrologic statistics proposed in the TEIS, and then to examine the issues of correlation with watershed conditions, regionalization, and information redundancy when ecological issues are included in the assessment of indicator redundancy. To this end, we used TEIS to identify hydrological statistics. Watershed conditions considered 
differences in geographic location, elevation, and area. Because elevation, coupled with location on East or West slopes, can produce rain shadow effects, and typhoon paths can produce intense, local, rainfall, this analysis considered watershed location as a possible key variable. Watershed area and elevation are commonly used in normalizing the analysis of hydrologic statistics. A critical factor used in station selection was that each watershed was largely undeveloped and that the record was sufficiently long to develop sound statistics. Our analysis included calculation of hydrological statistics recommended by the TEIS, assessment of the differences among watersheds due to location, area and elevation, cluster grouping of stations based on hydrologic statistics, and the assessment of information redundancy.

\section{Physical setting}

Taiwan is located in the North Pacific Ocean sub-tropical jet stream monsoon district. The island is $394 \mathrm{~km}$ long, $144 \mathrm{~km}$ at its widest point, and shaped like a leaf with a total area of nearly $36,000 \mathrm{~km}^{2}$. A general description finds mountains to the East and plains to the West. The most important feature of Taiwan's topography is the range of mountains running from the northeast corner to the Southern tip of the island. Steep slopes and mountains over $1000 \mathrm{~m}$ high constitute about $31 \%$ of the island's land area; hills and terraces between 100 and $1000 \mathrm{~m}$ above sea level make up 38\% of the land area; and alluvial plains below $100 \mathrm{~m}$ in elevation, where most communities, farming activities, and industries are concentrated, account for the remaining 31\%. The longest river in Taiwan is only $176 \mathrm{~km}$ long, which drops from near $4000 \mathrm{~m}$ to sea level over that distance. The annual average rainfall is $2515 \mathrm{~mm}$, about three times the world annual average. Rainfall is seasonal nearly $78 \%$ of the rainfall occurring from the end of spring to the beginning of autumn (May-October). There are known differences in rainfall distribution from the North to the South and with elevation. Fig. 1 shows the topography and the annual average isohyets and five administrative management regions. Isohyets are derived from the monthly rainfall distribution records for the period of 1971-2006. The observed differences in rainfall produce seasonal flow periodicity with dry periods from November to April, lasting as long as 6 months. In addition to geographic and seasonal influences on hydrology, typhoon passage influences rainfall. Typhoons occur with an average frequency of 3.5/year. Typhoon related rainfall has been recorded at over $1000 \mathrm{~mm} /$ day. Fig. 2 shows a typical storm hydrograph in Taiwan. The typical typhoon-related flow has extremely high flow stages in hydrographs lasting for less than a day to a few days. Few or many watersheds may be affected by a typhoon depending on the path and speed of transit. This complex and dynamic hydrologic environment provides a major physical challenge for the 163 freshwater fish species known in Taiwan. Further, the hydrologic environment has also promoted an active flood defense and engineering management of all rivers flowing through populated areas leading to the

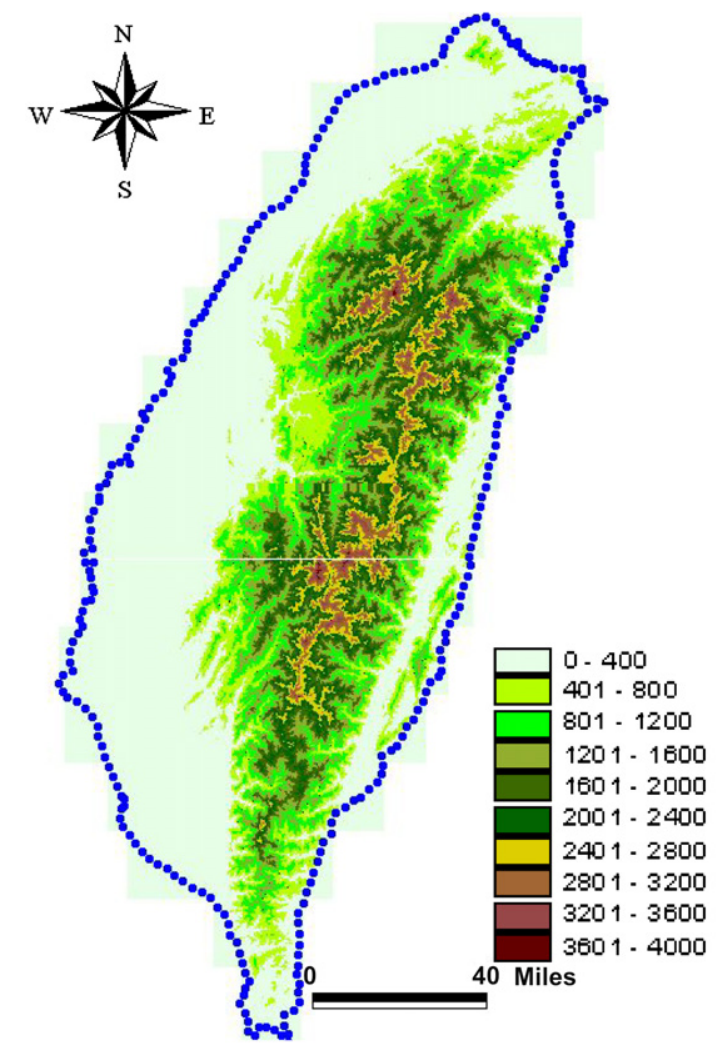

a

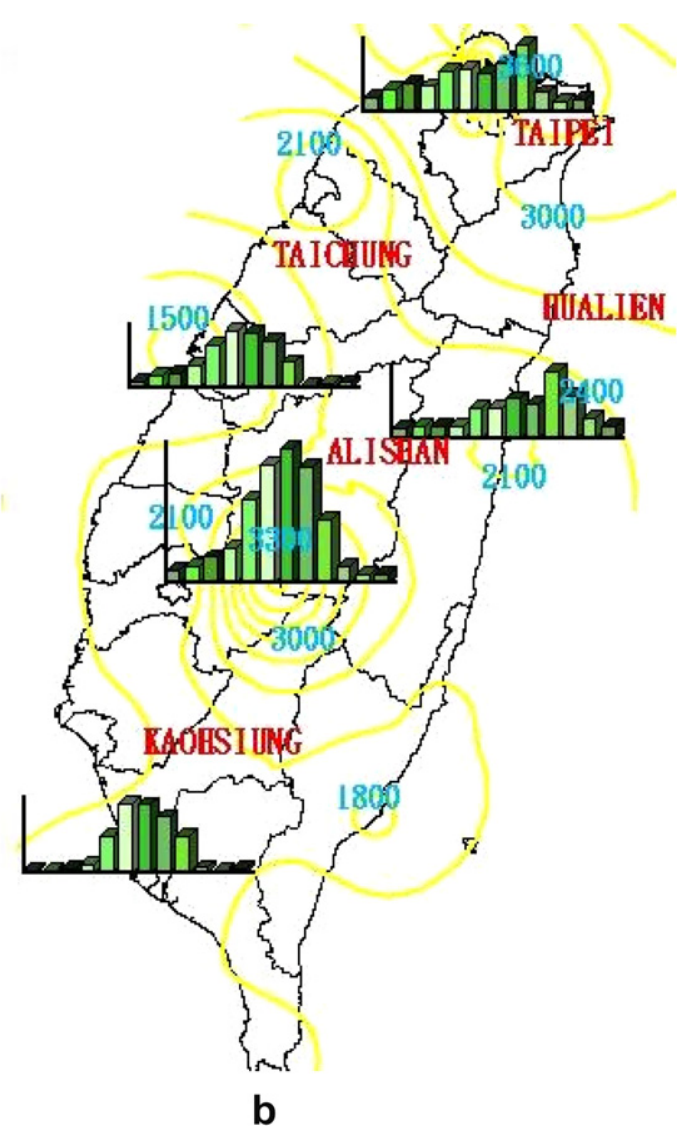

Figure 1 (a) Topography and (b) annual isohyets and rainfall distributions in Taiwan. 


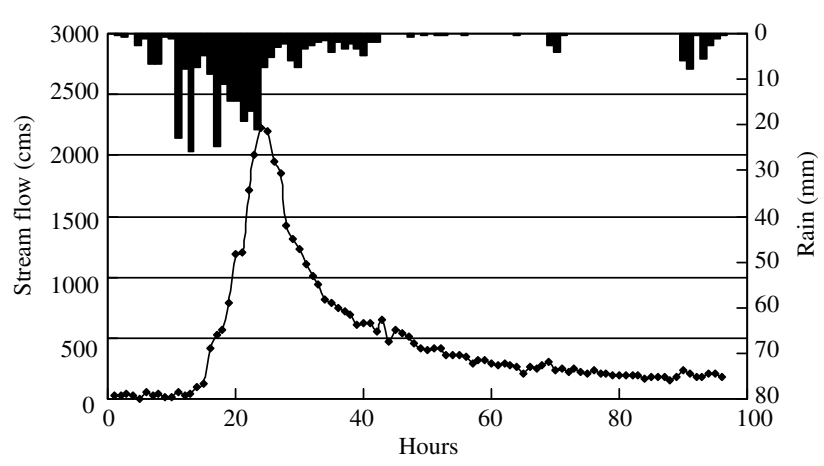

Figure 2 A typical storm's hydrograph in Shihmen reservoir, Taiwan $(2000 / 08 / 22 \sim 25$ Bills Typhoon).

modification of many watersheds. The undisturbed watersheds selected for this analysis were watersheds not subject to major hydrologic alteration or development that would be expected to alter flow characteristics.

\section{Taiwan ecohydrology indicators}

The suite of hydrological statistics selected for analysis in this paper is taken from the Taiwan ecohydrology indicator system (TEIS). The development of the TEIS was based on the considerations of Taiwan-specific factors. For example, the general flow statistics reflect the 10-day averaging period used by Taiwan's Water Resources Agency in reservoir management as well as a traditional reference time frame in the Chinese agricultural society. Statistics for dry and wet seasons were identified to address sub-tropical seasonality in Taiwan. Time periods for duration and frequency were set based on the typical storm characteristics and the needs of the fish community as identified by an autecology matrix (Suen and Herricks, 2006). Trend statistics were developed based on the fish species life history and were defined for different locations in the watershed based on fish community characteristics. The resulting indicator system provides a means to integrate hydrologic, ecological, and human management influences using a new synthesis of hydrologic statistics and provides a useful tool for the ecosystem based water resources management in Taiwan (Chang and Herricks, 2005).

The TEIS includes 35 hydrologic statistics for magnitude, frequency, duration, rate of change, and timing. Reflecting flow management in Taiwan means that stream flow statistics are summarized for 10 -day periods. These 36 items that provide indicators for general flow, and the four indicators focused on Julian date, were not used in the analysis. Mean stream flows were simply statistics based on management convenience and were only used in general flow description. Although timing issues are recognized as important in ecohydrologic analysis, the inherent variability in fixing a Julian date produced by typhoons limited the use in analysis procedures. Like Poff (1996), timing was shifted to a secondary analysis that would be specific for the species targeted, which is not the focus of this paper. Hydrologic statistics follow TEIS grouping for the rate of change, high/low duration, frequency, and duration. Table 1 provides a listing of the 30 of the TEIS hydrologic indicators used in this analysis.
Examples of how these hydrological statistics are expected to relate to organisms and communities are provided by Suen (2005) and Suen and Herricks (2006), but are summarized here for the readers' convenience. In the TEIS general flow statistics define seasonality and can be related to general habitat conditions. Trends in flow provide an indication of how habitat needs for spawning, juvenile rearing, or adult maintenance is met. The rate of change statistics provides measures of habitat disruption or the duration stability of habitat needed to complete organism life history. For example, rapid changes in discharge may remove organisms through washout while more gradual change in discharge may provide environmental cues for migration or reproduction (Cushman, 1985; Welcomme, 1985). Using the mean of all positive and negative differences between consecutive values provides a measure of the rate of change in habitat supporting the analysis of the general suitability of those conditions for the maintenance of the target aquatic community.

Statistics for high/low flow magnitude and duration provide information on floods and droughts, which can have significant effects on riverine species. Typhoon events, although large, pass quickly so that 3-day average values reflect typhoon influences in Taiwan's wet season. Monthly statistics provide a means of tracking within season trends while 1- and 3-day averages allow the definition of event characteristics. Examples of ecological connections to flow include elevated flows that inundate floodplains producing the needed habitat for spawning, nursery of fry and juveniles, and foraging habitat. High magnitude, short duration events will inundate floodplains, but will also create velocity and turbulence conditions in the channel that lead to injury or death of fish (Ward et al., 1999; Harvey, 1987). Correspondingly, the extended duration of high flows may exceed the capacity for maintaining location and the duration of low flows produces reduced channel habitat and an increased risk of loss of organisms due to changing water quality or predation risk (Magoulick and Kobza, 2003; Herricks, 1996).

Frequency statistics are important ecologically because riverine species are adjusted to change but more frequent events present a challenge to organisms. Increasing frequency reduces the recovery time between events leading to an increased effect of any single event. Increasing frequency eventually means that duration and frequency are the same, as in continuous exposure scenarios. Frequency statistics are used to relate events and characterize habitat stability when a single event, or multiple events with lower magnitude, can be expected to produce similar effects. The actual effect of event frequency is complicated because riverine species have evolved the capacity to deal with the change in their environment. In fact, maintenance of a sustainable ecosystem may actually be dependent on periodic disturbances. Increasing or decreasing frequency can lead to ecological damage (Ward and Stanford, 1983). Therefore, the number of high/low flow events and the number of hydrograph slope reversals in the dry and wet seasons are important statistics in the TEIS that help identify natural levels of disturbance needed to sustain ecological integrity. Because the life span of most endemic species in Taiwan is in the order of 3 years, the numbers of high/low flow events within three consecutive years are the focus of the TEIS. 


\begin{tabular}{|c|c|c|c|c|c|c|c|c|}
\hline & \multirow{2}{*}{\multicolumn{2}{|c|}{ 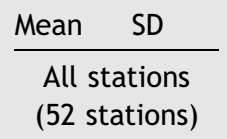 }} & \multicolumn{3}{|l|}{$K$-means } & \multicolumn{3}{|l|}{ SOM } \\
\hline & & & $\# 1$ (5 stations) & \#2 (15 stations) & \#3 (32 stations) & \#1 (13 stations) & \#2 (15 stations) & \#3 (24 stations) \\
\hline \multicolumn{9}{|l|}{ Watershed characteristics } \\
\hline Area $\left(\mathrm{km}^{2}\right)$ & 236 & 200 & 639 & 315 & 136 & 473 & 194 & 112 \\
\hline Elevation (m) & 393 & 455 & 234 & 459 & 386 & 342 & 466 & 377 \\
\hline TEIS characteristic & \multicolumn{8}{|c|}{ Group 1 - Differences between consecutive values } \\
\hline $\begin{array}{l}\text { 1. Mean of all positive differences between } \\
\text { consecutive values in dry season }(\mathrm{cms})\end{array}$ & 3.22 & 2.50 & 9.11 & 3.85 & 2.00 & 6.45 & 2.60 & 1.75 \\
\hline $\begin{array}{l}\text { 2. Mean of all positive differences between } \\
\text { consecutive values in wet season }(\mathrm{cms})\end{array}$ & 22.48 & 20.85 & 72.64 & 25.93 & 13.02 & 48.38 & 19.67 & 9.57 \\
\hline $\begin{array}{l}\text { 3. Mean of all negative differences between } \\
\text { consecutive values in dry season }(\mathrm{cms})\end{array}$ & 1.29 & 0.89 & 3.08 & 1.47 & 0.93 & 2.27 & 0.98 & 0.92 \\
\hline \multirow{2}{*}{$\begin{array}{l}\text { 4. Mean of all negative differences between } \\
\text { consecutive values in wet season }(\mathrm{cms})\end{array}$} & 7.63 & 6.01 & 21.26 & 8.14 & 5.26 & 14.45 & 6.57 & 4.37 \\
\hline & \multicolumn{8}{|c|}{ Group 2 - High/low flow event magnitudes } \\
\hline 5. Dry season 1-day minimum (cms) & 2.73 & 2.64 & 7.41 & 4.80 & 1.03 & 6.47 & 2.52 & 0.73 \\
\hline 6. Dry season 10 -day minimum (cms) & 3.04 & 2.88 & 8.23 & 5.28 & 1.18 & 7.13 & 2.81 & 0.87 \\
\hline 7. Dry season 30 -day minimum (cms) & 3.51 & 3.21 & 9.33 & 6.00 & 1.42 & 8.05 & 3.25 & 1.08 \\
\hline 8. Dry season 90 -day minimum (cms) & 4.64 & 4.09 & 12.35 & 7.63 & 2.04 & 10.32 & 4.27 & 1.64 \\
\hline 9. Dry season 1-day maximum (cms) & 58.6 & 46.4 & 165.3 & 77.5 & 33.14 & 122.1 & 47.1 & 29.7 \\
\hline 10. Dry season 10 -day maximum $(\mathrm{cms})$ & 26.7 & 20.1 & 69.7 & 38.0 & 14.7 & 55.3 & 22.7 & 12.9 \\
\hline 11. Dry season 30 -day maximum $(\mathrm{cms})$ & 16.8 & 12.5 & 41.9 & 25.0 & 9.06 & 34.7 & 14.9 & 7.80 \\
\hline 12. Wet season 1-day minimum (cms) & 3.57 & 3.50 & 10.2 & 5.83 & 1.46 & 8.38 & 3.34 & 0.96 \\
\hline 13. Wet season 10 -day minimum $(\mathrm{cms})$ & 4.34 & 4.11 & 12.4 & 6.84 & 1.92 & 9.96 & 4.05 & 1.32 \\
\hline 14. Wet season 30 -day minimum (cms) & 6.51 & 6.17 & 19.3 & 9.42 & 3.15 & 14.6 & 6.07 & 2.17 \\
\hline 15. Wet season 1-day maximum (cms) & 411.9 & 371.5 & 1244 & 485.7 & 247.2 & 852.8 & 386.2 & 176.2 \\
\hline 16. Wet season 3-day maximum $(\mathrm{cms})$ & 250.2 & 226.2 & 761.3 & 303.1 & 145.5 & 527.1 & 234.3 & 102.9 \\
\hline 17. Wet season 10 -day maximum (cms) & 121.7 & 190.4 & 365.5 & 153.1 & 69.0 & 259.6 & 113 & 49.0 \\
\hline \multirow[t]{2}{*}{ 18. Wet season 30 -day maximum $(\mathrm{cms})$} & 64.6 & 56.5 & 190.1 & 83.4 & 36.2 & 137.9 & 59.8 & 26.0 \\
\hline & \multicolumn{8}{|c|}{ Group 3 - Frequency of high/low flow events and reversals } \\
\hline $\begin{array}{l}\text { 19. Number of low flow events within each dry } \\
\text { season (times) }\end{array}$ & 1.30 & 2.04 & 0.36 & 0.21 & 1.96 & 0.25 & 0.48 & 2.41 \\
\hline $\begin{array}{l}\text { 20. Number of low flow events within each wet } \\
\text { season (times) }\end{array}$ & 3.76 & 3.27 & 2.84 & 1.81 & 4.81 & 2.24 & 2.17 & 5.59 \\
\hline $\begin{array}{l}\text { 21. Number of high flow events within each dry } \\
\text { season (times) }\end{array}$ & 2.97 & 1.64 & 2.17 & 1.99 & 3.56 & 2.00 & 2.33 & 3.91 \\
\hline \multirow{2}{*}{$\begin{array}{l}\text { 22. Number of high flow events within each wet } \\
\text { season (times) }\end{array}$} & 5.01 & 1.86 & 4.79 & 3.74 & 5.64 & 4.15 & 4.07 & 6.05 \\
\hline & & & & & & & \multicolumn{2}{|c|}{ (continued on next page) } \\
\hline
\end{tabular}




\begin{tabular}{|c|c|c|c|c|c|c|c|c|}
\hline & Mean & SD & \multicolumn{3}{|l|}{$K$-means } & \multicolumn{3}{|l|}{ SOM } \\
\hline & \multicolumn{2}{|c|}{$\begin{array}{l}\text { All stations } \\
\text { (52 stations) }\end{array}$} & $\# 1$ (5 stations) & \#2 (15 stations) & \#3 (32 stations) & \#1 (13 stations) & \#2 (15 stations) & \#3 (24 stations) \\
\hline $\begin{array}{l}\text { 23. Number of low flow events within } \\
\text { consecutive } 3 \text { years (times } / 3 \text { years) }\end{array}$ & 14.07 & 15.03 & 11.74 & 3.95 & 19.18 & 7.01 & 7.16 & 22.36 \\
\hline $\begin{array}{l}\text { 24. Number of high flow events within } \\
\text { consecutive } 3 \text { years (times } / 3 \text { years) }\end{array}$ & 22.65 & 9.23 & 19.98 & 16.11 & 26.14 & 17.57 & 18.12 & 28.22 \\
\hline $\begin{array}{l}\text { 25. Number of hydrologic reversals in } \\
\text { dry season (times/year) }\end{array}$ & 39.16 & 10.46 & 38.94 & 37.88 & 39.80 & 37.49 & 37.30 & 41.07 \\
\hline \multirow{2}{*}{$\begin{array}{l}\text { 26. Number of hydrologic reversals in } \\
\text { wet season (times/year) }\end{array}$} & 46.93 & 10.89 & 45.88 & 43.28 & 48.81 & 43.79 & 43.45 & 50.60 \\
\hline & \multicolumn{8}{|c|}{ Group 4 - High/low flow event duration } \\
\hline $\begin{array}{l}\text { 27. Mean duration of low flow events in } \\
\text { dry season (days/time) }\end{array}$ & 4.20 & 6.34 & 2.37 & 0.80 & 6.07 & 1.45 & 2.16 & 7.02 \\
\hline $\begin{array}{l}\text { 28. Mean duration of high flow events in } \\
\text { dry season (days/time) }\end{array}$ & 4.07 & 1.29 & 3.77 & 3.61 & 4.33 & 3.65 & 4.14 & 4.28 \\
\hline $\begin{array}{l}\text { 29. Mean duration of low flow events in } \\
\text { wet season (days/time) }\end{array}$ & 6.62 & 3.06 & 6.80 & 4.84 & 7.43 & 5.65 & 6.19 & 7.46 \\
\hline $\begin{array}{l}\text { 30. Mean duration of high flow events in } \\
\text { wet season (days/time) }\end{array}$ & 4.17 & 1.20 & 4.08 & 5.08 & 3.76 & 4.71 & 4.64 & 3.60 \\
\hline
\end{tabular}


Ecosystems are highly dependent on the timing of flows. For example, in fish species that spawn once a year, this spawning may be keyed to flow change, temperature, and maintenance of specified conditions to provide critical habitat for successful spawning and fry development. Thus, flow timing is critical to species spawning, egg hatching, or migration (Nesler et al., 1988; Naesje et al., 1995), especially in areas where periodic floods are expected (Tew et al., 2002). For these reasons, the Julian date of flow events is an important data point to relate organism life history and flow.

\section{Materials and methods}

\section{Method of selection of stations}

For a small island, Taiwan has a relatively dense network of flow monitoring stations. The watershed characteristics of 430 stations were reviewed and stations subject to modified flows from reservoirs or major irrigation systems were eliminated. A final set of 52 stations included records from 23 largely unaltered watersheds, which are intended to support the identification of natural flow regimes in these watersheds. Using the daily average flow from each station, TEIS indicators were calculated, and the results are provided in Table 1.

To provide an initial organization, the TEIS statistics were grouped using the management regions established by the Taiwan Water Resources Agency, North, middle, Southern, and Eastern. This initial organization reflected mainly political divisions although agency regions did reflect watershed boundaries and physiographic differences with the Eastern region characterized by a narrow coastal plain and steep, mountain slopes, while the North, middle, and Southern regions are the divisions of the West coast where coastal plains are broad with high density population centers.

Measurements were made of watershed area for each gauging station and the elevation of the gage was determined. Although other characteristics of watersheds were measured, only the area and elevation were used as independent variables in this analysis. Watershed areas ranged from 100 to $900 \mathrm{~km}^{2}$ with the majority less than $300 \mathrm{~km}^{2}$, and elevation ranged from sea level to $1800 \mathrm{~m}$, Fig. 3 .

\section{Analytical procedures}

A general question facing researchers in many areas of inquiry is how to organize the observed data into meaningful structures, that is, to develop groups of similar stations for a more detailed analysis. Cluster analysis is a useful technique to identify groups that both minimize within-group variation for data in a cluster and maximize between-group variation to identify potential differences between clusters. The advantage of cluster analysis is that it is a technique that can be applied without bias to discover structures in data without providing an explanation/interpretation of the cluster groupings. Clustering techniques have been applied to a wide variety of research problems. In this study, we apply two commonly used clustering algorithms, namely $K$-means clustering and the self-organizing map (SOM) clus-
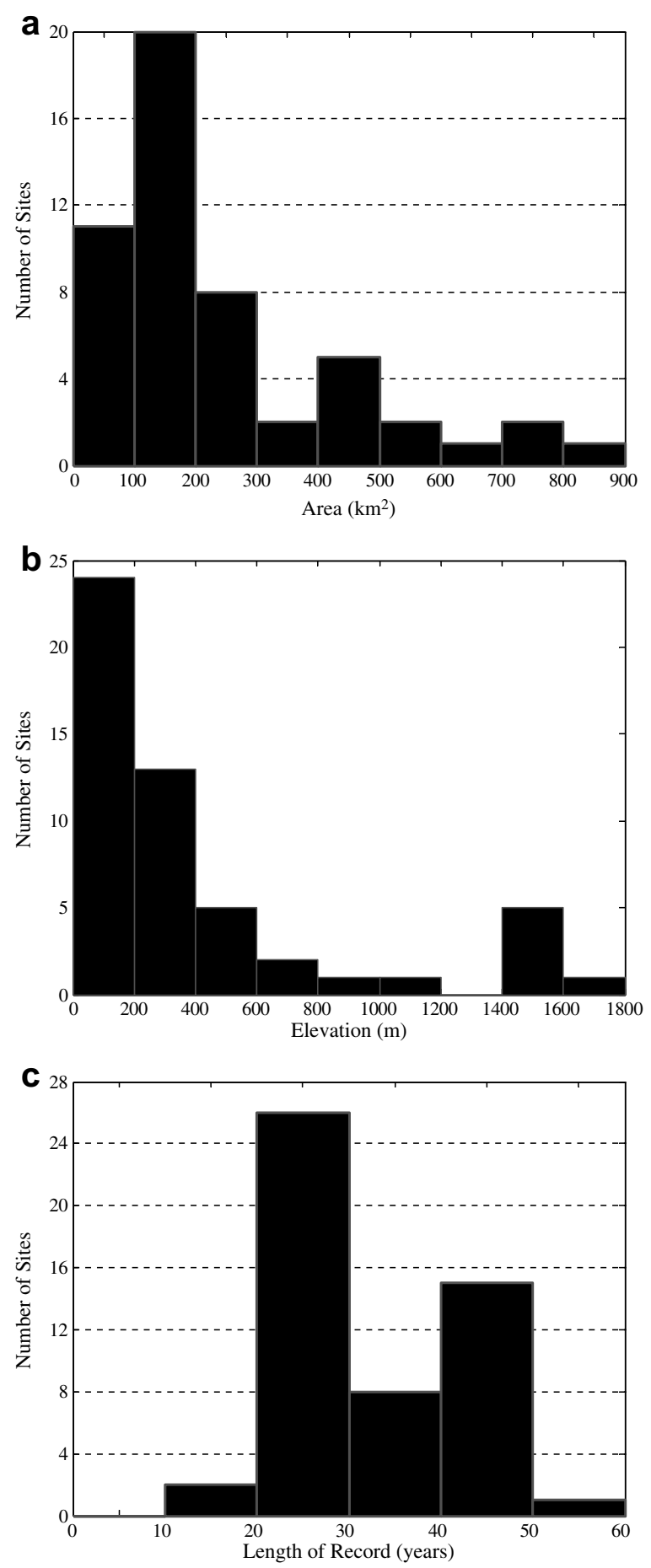

Figure 3 Numbers of gauging sites with (a) basin areas (b) basin elevation, and (c) lengths of record.

tering. The values shown in Table 1 are the result of $K$ means or SOM clustering providing the average values for the hydrological statistics contained in that cluster group. A brief summary of the two clustering algorithms used in this analysis is given as follows.

\section{K-means clustering}

$K$-means clustering uses an algorithm to classify objects based on a defined number $(K)$ of groups, where $K$ is the 
positive integer number. The grouping is done by minimizing the sum of squares of distances between the data and the corresponding cluster centroid. The algorithm is described briefly as follows:

(1) Begin with a decision on the value of $K=$ number of clusters.

(2) Place $K$ points into the space represented by the objects that are being clustered. These points represent the initial group centroids.

(3) Assign each object to the group that has the closest centroid.

(4) When all objects have been assigned, recalculate the positions of the $K$ centroids.

(5) Repeat steps 3 and 4 until the centroids no longer move. This produces a separation of the objects into groups from which the metric to be minimized can be calculated.

\section{SOM clustering}

SOM clustering uses an algorithm introduced by Kohonen (1982). SOM generates lower dimensional topological ordered maps of input data through learning, which is very useful for analyzing high-dimension data. Once SOM is determined, the output of the network to the input vectors can be recalled from the classifying results memorized in the network. The SOM algorithm is an unsupervised classification that uses competitive learning strategy to adjust the connected weights between the input and the hidden layers and to form a topographically ordered map in the hidden layer. Different from other clustering methods for unsupervised data, SOM can be highly non-linear, directly showing the similar input vectors in the source space by points (Chang et al., 2007). The learning algorithm of the training connected weights in SOM is summarized as follows

(1) Initialize network weight vectors.

(2) Randomly choose an input vector from input space.

(3) Determine the winning neuron by calculating the Euclidean distance between the input vector and the weight vectors of all neurons in the hidden layer.

(4) Adjust the weight vector of the winner as well as the weight vectors of its neighboring neurons according to the learning rule.

(5) Iterate the procedures from 2 until the weight vectors stabilize.

After a large number of iterations, each input vector is mapped onto a specific neuron in the hidden layer in the way that the weight vector of the neuron is closer to the input vector.

\section{Cluster group determination}

An important issue in cluster analysis is the selection of the number of cluster groups that are used to organize data. Three common test statistics were used to identify a cluster, the root-mean-square standard deviation (RMSSTD), the $R$-squared (RS), and the semipartial $R$-squared (SPRSQ). The RMSSTD is a measure of homogeneity within clusters based on Eq. (1). Large values of RMSSTD indicate that the clusters are not homogeneous
RMSSTD $=\sqrt{\frac{(n-1) \sum_{i=1}^{P} S_{i}^{2}}{P(n-1)}}=\sqrt{\frac{\sum_{i=1}^{P} S_{i}^{2}}{P}}$

$P$ is the number of clusters, $n$ is the sample size, and $S_{i}$ is the standard deviation of $i$ th cluster.

The $R$-squared metric provides a measure of the extent to which clusters are different from each other. The value of RS lies between 0 and 1 with values close to 1 indicating a high difference between clusters

$R^{2}=1-\frac{\sum_{k=1}^{G} \sum_{i \in G_{k}}\left\|x_{i}-\bar{x}_{k}\right\|^{2}}{\sum_{i=1}^{n}\left\|x_{i}-\bar{x}\right\|^{2}}$

where $G$ is the number of clusters in hierarchical level. The RS always decreases with the number of clusters.

The SPRSQ compares clustering results and provides a measure of the difference between two results. When the SPRSQ is larger, this indicates that the result of the first cluster is preferred

SPRSQ $=\frac{\frac{n_{\mathrm{p}} \cdot n_{\mathrm{q}}}{n_{\mathrm{r}}}\left\|\bar{x}_{\mathrm{p}}-\overline{\boldsymbol{x}}_{\mathrm{q}}\right\|^{2}}{\sum_{\mathrm{i}=1}^{n}\left\|\boldsymbol{x}_{\mathrm{i}}-\overline{\boldsymbol{x}}\right\|^{2}}$

where $n_{r}=n_{\mathrm{p}}+n_{\mathrm{q}}, n_{\mathrm{p}}$ and $n_{\mathrm{q}}$ are the samples of cluster $\mathrm{p}$ and cluster q. SPRSQ denotes the difference between the previous $R^{2}$ and the present $R^{2}$.

The relative change in the values of the RMSSTD, RS, and SPRSQ statistics as the number of clusters increase can be useful in determining the number of clusters. In our analysis, we calculated statistics at each stage in the clustering algorithm, which allowed plotting the values against the number of clusters. A marked decrease or increase for RMSSTD, RS and SPRSQ, respectively, was the criterion used to identify when a satisfactory number of clusters was selected (Sharma, 1996).

\section{Results and discussion}

The results of the calculation of TEIS hydrologic statistics for the 52 gauging stations are provided in Table 1 . The mean watershed area was $236 \mathrm{~km}^{2}$ and the mean elevation was $393 \mathrm{~m}$ indicating that undisturbed watersheds were small and generally located in higher elevations. Table 1 provides the mean and standard deviation for 30 hydrologic statistics of the TEIS. The mean streamflow for the 36 tenday period of the TIES is replaced with the average fractional flow by month as shown in Fig. 4. The remainder of the table provides the average values of watershed hydro-

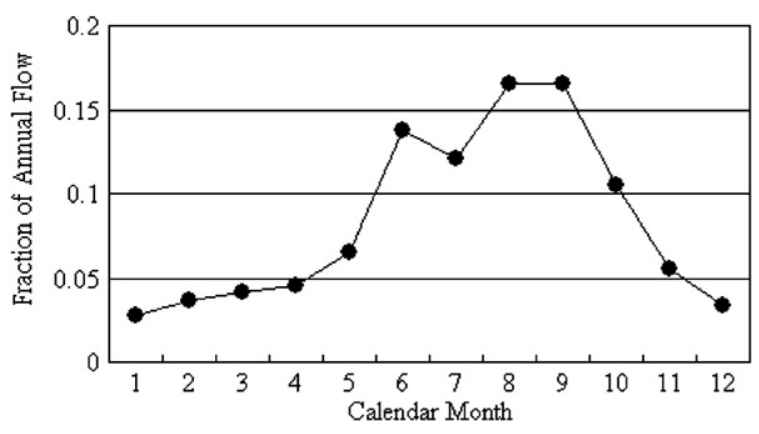

Figure 4 Average fractional monthly flows by month. 
logic statistics for the stations grouped by $K$-means and SOM clustering.

When watershed area is considered, the majority of the watersheds in this analysis (32) had an average area of less than $140 \mathrm{~km}^{2}$, Table 1, with the typical record length of 2050 years, Fig. 3c. The 30 TEIS indicators shown in Tables 1 and 2 are grouped in categories considering flow variability based on differences in consecutive values, high/low flow statistics based on frequency analysis, event frequency, and high and low flow event duration. The TEIS statistics are numbered $1-30$ to relate to Fig. 7 where the relative normalized value of cluster averages is compared. Fig. 7 also demonstrates the capacity of the clustering algorithm to group similar stations and provides cluster groupings for these data.

\section{Characteristics of flow in Taiwan rivers}

Flow conditions in Taiwan rivers can be characterized based on general watershed conditions identified in this analysis, from the average fractional monthly flows determined for all 52 stations, and TEIS statistical summaries. Because of the limited river length flow travel times are short. Watershed selection minimized human influences supporting the natural flow regime analysis so that seasonality of stream flow is influenced mostly by the seasonal cycle of precipitation. In the wet season (May-October), precipitation is in the form of typhoons and/or high intensity rainfall events producing daily rainfall values of hundreds to over a thousand millimeters. Although snow is present at high elevations, the snowmelt contribution to hydrology is limited to winter months in high elevations. The average seasonal distribution of flow finds about $80 \%$ of the flow occurs in the wet season with the highest fraction during August and September, Fig. 4. TEIS statistics show that the rate of flow rise is two or three times of the falling rate in both seasons, while the flow rise and fall in wet season are about seven times of dry season, respectively. The flow rising rate is 3.22 (dry season) and 22.48 (wet season), and the falling rate is 1.29 (dry season) and 7.63 (wet season), Table 1,

Table 2 Correlation Coefficients between TEIS parameters and physiographic variables - area and elevation

\begin{tabular}{|c|c|c|}
\hline & Area $\left(\mathrm{km}^{2}\right)$ & Elevation $(\mathrm{m})$ \\
\hline \multicolumn{3}{|l|}{ Group 1 - Differences between consecutive values (cms) } \\
\hline Mean of all positive differences between consecutive values in dry season & 0.854 & -0.094 \\
\hline Mean of all positive differences between consecutive values in wet season & 0.881 & -0.196 \\
\hline Mean of all negative differences between consecutive values in dry season & 0.847 & -0.219 \\
\hline Mean of all negative differences between consecutive values in wet season & 0.901 & -0.311 \\
\hline \multicolumn{3}{|l|}{ Group 2 - High/low flow event magnitudes (cms) } \\
\hline Dry season 1 -day minimum & 0.900 & -0.068 \\
\hline Dry season 10 -day minimum & 0.905 & -0.083 \\
\hline Dry season 30 -day minimum & 0.903 & -0.093 \\
\hline Dry season 90 -day minimum & 0.910 & -0.103 \\
\hline Dry season 1-day maximum & 0.892 & -0.163 \\
\hline Dry season 10 -day maximum & 0.923 & -0.090 \\
\hline Dry season 30 -day maximum & 0.924 & -0.061 \\
\hline Wet season 1-day minimum & 0.946 & -0.003 \\
\hline Wet season 10-day minimum & 0.955 & -0.022 \\
\hline Wet season 30-day minimum & 0.957 & -0.056 \\
\hline Wet season 1-day maximum & 0.928 & -0.227 \\
\hline Wet season 3-day maximum & 0.926 & -0.210 \\
\hline Wet season 10-day maximum & 0.929 & -0.182 \\
\hline Wet season 30-day maximum & 0.939 & -0.169 \\
\hline \multicolumn{3}{|l|}{ Group 3 - Frequency of high/low flow events and reversals } \\
\hline Number of low flow events within each dry season (times) & -0.278 & $0.431(\# 1)$ \\
\hline Number of low flow events within each wet season (times) & -0.257 & $0.758(\# 2)$ \\
\hline Number of high flow events within each dry season (times) & -0.281 & $0.317(\# 1)$ \\
\hline Number of high flow events within each wet season (times) & -0.257 & $0.653(\# 2)$ \\
\hline Number of low flow events within consecutive 3 years (times $/ 3$ years) & -0.213 & $0.582(\# 1)$ \\
\hline Number of high flow events within consecutive 3 years (times/ 3 years) & -0.203 & $0.528(\# 2)$ \\
\hline Number of hydrologic reversals in dry season (times/year) & 0.038 & $0.511(\# 1)$ \\
\hline Number of hydrologic reversals in wet season (times/year) & -0.067 & $0.253(\# 1)$ \\
\hline \multicolumn{3}{|l|}{ Group 4 - High/low flow event duration (days/time) } \\
\hline Mean duration of low flow events in each dry season & -0.207 & $0.449(\# 1)$ \\
\hline Mean duration of high flow events in each dry season & -0.129 & $0.452(\# 3)$ \\
\hline Mean duration of low flow events in each wet season & -0.125 & $0.468(\# 3)$ \\
\hline Mean duration of high flow events in each wet season & 0.183 & $0.680(\# 2)$ \\
\hline
\end{tabular}

\#1: a log transformation; \#2: a power transformation; and \#3: an exponent transformation. 
Group 1. The general pattern of short high flow events and long duration low flows is confirmed. Cluster groups have stations with high average values in Cluster 1 with decreasing values in Clusters 2 and 3, Table 1.

\section{High/low flow event magnitudes}

High and low flow statistics in the TEIS focus on the frequency of occurrence for wet and dry season minima and maxima, Table 1, Group 2. During the dry season, the average minimum flow for 1-90 days is all less than $5 \mathrm{~m}^{3} / \mathrm{s}$, while the average maximum flows of 1-30 days are between 25 and $60 \mathrm{~m}^{3} / \mathrm{s}$. During the wet season, the average minimum flow for 1-30 days is near $5 \mathrm{~m}^{3} / \mathrm{s}$; however, the average maximum flows of 1-30 days can be larger than several $100 \mathrm{~m}^{3} / \mathrm{s}$. Seven stations had maximum flow values higher than $1000 \mathrm{~m}^{3} / \mathrm{s}$ in the wet season, while 18 stations had a 1 -day minimum flow of less than $1 \mathrm{~m}^{3} / \mathrm{s}$ in the dry season. In addition to ecological issues, low streamflow estimates are required for a variety of water resource management purposes, particularly the diversion of water to agricultural use. This analysis suggests that minimum flows will be limiting in all watersheds with over $60 \%$ of the watersheds in this analysis providing consistent low flow conditions.

\section{Frequency of high/low flow events and reversals}

TEIS statistics indicate that the number of low flow events ranges from 1.30 to 3.76 times per/year, while the number of high flow events ranges from 2.97 to 5.01 times per/year, Table 1, Group 3. The numbers of low and high flow events for consecutive 3 year periods are 14.07 and 22.67. The numbers of hydrologic reversals in dry and wet seasons are 39.16 and 46.93 , both with a standard deviation of around 10. Fig. 5 summarizes flow reversals in the dry and wet seasons for all 52 stations.

Suen (2005) defined a low flow event as the flow which is lower than $25 \%$ of the average discharge, while the high flow event is greater than $200 \%$ of the average discharge. These results confirm that both the number of events and the corresponding flow variability are greater in the wet season than that in the dry season. Station by station analysis found four stations, all in South Taiwan, that have low, unvarying flows. The flow reversal statistic is indicative of a frequency

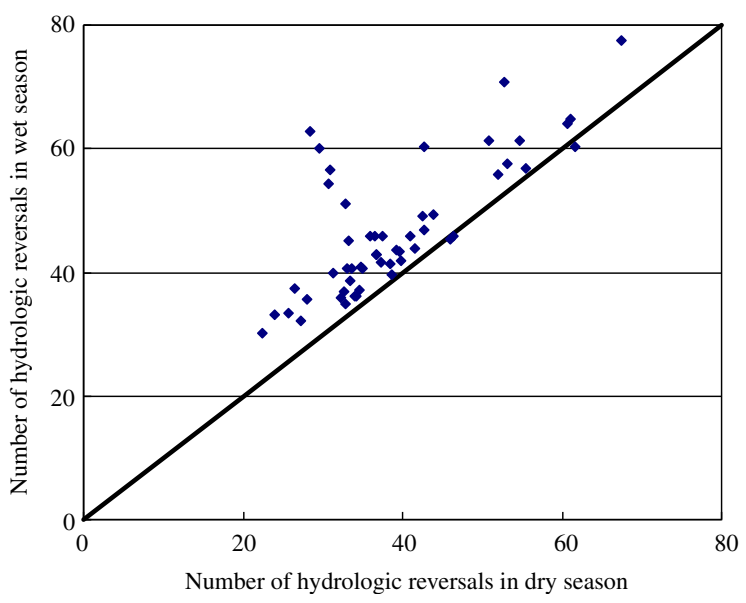

Figure 5 The relation of hydrological reversal in dry season and wet season. of habitat change and a good indicator of the overall habitat stability. Analysis results indicate that flow reversals may average more than 85 times per year indicating few weeks pass without flow related habitat change in even undisturbed watersheds in Taiwan.

\section{Duration}

The mean duration of low flow events in the dry season is in the order of 4 days with a high standard deviation. The mean duration of low flow in the wet season is in the order of 6 days with a standard deviation of about 3 , which is one half of the dry season standard deviation. High flow durations were 4 days for both dry and wet seasons with a standard deviation near one. The stations in Cluster 3 tended to have higher low flow event durations while the high flow event durations were near station averages. These results are generally consistent with the analysis of flow reversals, which suggest changes occurring weekly, but with a short duration.

\section{Summary}

The natural flow conditions for 52 watersheds in Taiwan have been effectively characterized by TEIS statistics. This analysis confirmed the seasonality of flow in Taiwan with distinct wet and dry periods. Increasing values for consecutive measurements averaged $3.22 \mathrm{cms}$ in the dry season and $22.48 \mathrm{cms}$ in the wet season indicating an expected higher flow variability in the wet season. The analysis of high/ low flows indicated that $1,10,30$, and 90 day low flows are all less than $5 \mathrm{~m}^{3} / \mathrm{s}$ with some low flows less than $1 \mathrm{~m}^{3} / \mathrm{s}$ in the dry season. Wet season minimum flows are also near $5 \mathrm{~m}^{3} / \mathrm{s}$ but maximum flow averages are as high as $411 \mathrm{~m}^{3} / \mathrm{s}$ with event maximum flows exceeding $1000 \mathrm{~m}^{3} / \mathrm{s}$. These flow characteristics describe a natural flow regime with low flows nearly the same in both the dry and the wet seasons punctuated by high flow events that are more than two orders of magnitude greater than low flow conditions. Frequency analysis finds that the number of low flow events ranges from 1 to 3 per/year, while the number of high flow events ranges from 3 to 5 per/year. A useful indicator of ecological condition is the flow reversal. The numbers of flow reversals in dry and wet seasons were 39.16 and 46.93 , respectively. These reversals characterize a flow environment that can be expected to fluctuate regularly in both dry and wet environments every few days. Event duration is short with low flow events lasting slightly longer in the wet season than the dry season (6 vs. 4 days). The wet season low flows are only slightly greater than dry season low flows, and the high flow events are typically shorter with very high maximum flows, reflecting the rapid passage of typhoon systems over the island. These results provide insight into the natural flow variability that supports populations of native fish.

\section{Cluster analysis}

Watersheds with similar values for hydrologic statistics were grouped together using $K$-means and SOM clustering algorithms. The relationships between the number of clusters produced by $K$-mean clustering were evaluated using RMSSTD, $R$-squared, and SPRSQ statistics (Fig. 6). These 
results indicate that when the number of clusters is smaller than 3 , the SPRSQ value increases, $R$-squared value drops, and RMSSTD value is high. We inferred from these results that the appropriate number of clusters was 3.

The three clusters of stations identified by $K$-means and SOM methods are shown in Table 1 and Fig. 7. The numbers of stations are 5, 15, 32 in $\mathrm{K}$-means clusters and 13, 15, 24 in SOM clusters. The average values for hydrological statistics from the stations grouped in $K$-means and SOM clusters are also provided in Table 1 , and standardized values represented in Fig. 7. Fig. 7 reveals that both methods produce three clusters for items 1-18 shown in Table 1 , and statistics related to the rate of change and flow frequency. SOM clustering grouped stations with less variability in each cluster and shows a clear distinction between the three clusters in all the 30 TEIS indicators. Comparing the results obtained by $K$-means, SOM suggested that the SOM provides a better clustering for TEIS parameters.

Table 1 presents the average values of TEIS statistics for the stations grouped in each cluster for both $\mathrm{K}$-means and SOM clustering. For both methods, Cluster 1 has stations with the largest average values for the rate of change and flow frequency statistics and smaller values for event frequency and event duration statistics. Cluster 3 generally has stations with the smallest values for the same statistics. The analysis of Table 1 confirms the similarity between clustering methods. The major difference is found in Cluster 2 where the $K$-means clustering has grouped stations with the smallest values for event frequency and event duration statistics. Event frequency and event duration statistics have stations with the smallest values in Cluster 1 using SOM clustering. a

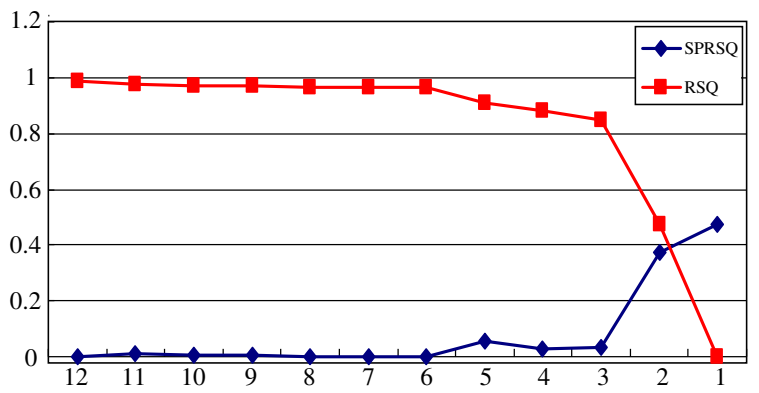

b

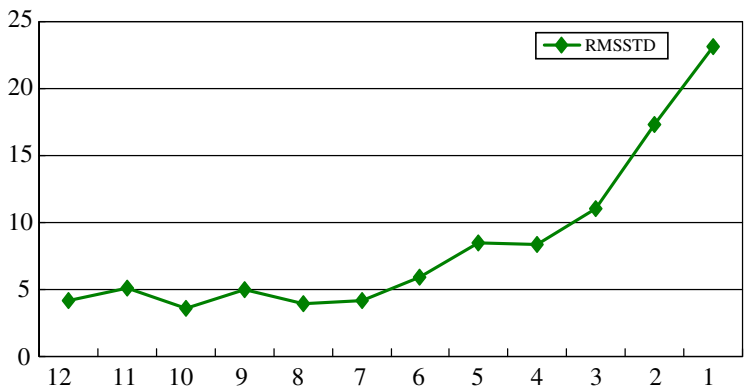

Figure 6 The relationships between the number of clusters and SPRSQ, RSQ, RMSSTD.

a

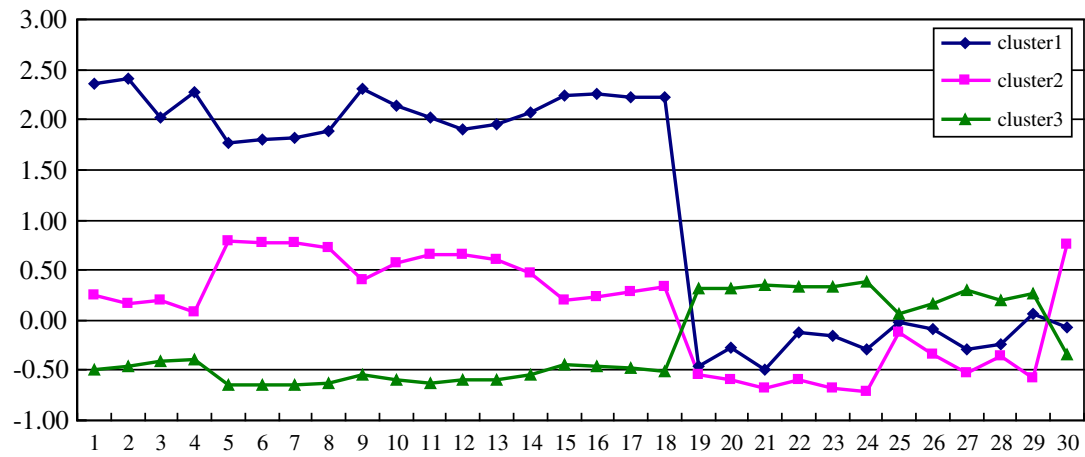

b

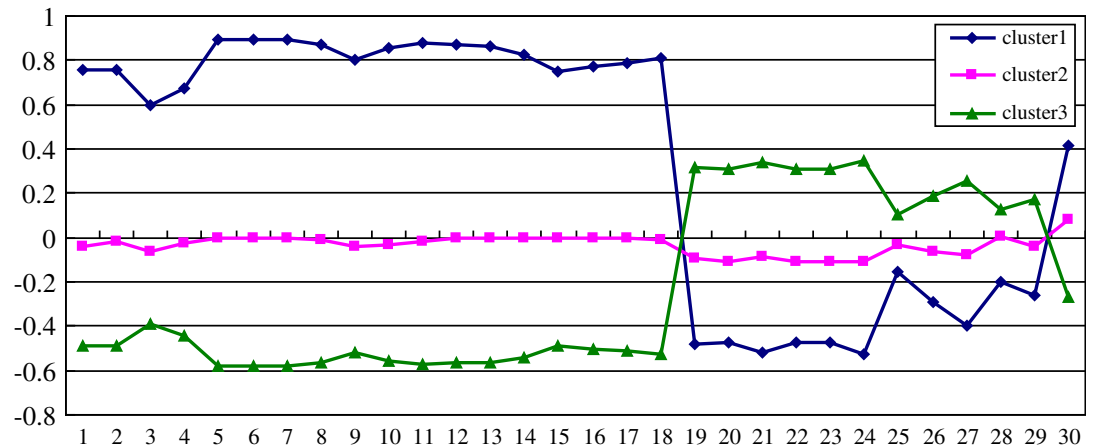

Figure 7 The standardized cluster centers of 30 TEIS parameters by (a) $K$-means and (b) SOM methods. 


\section{Geographic distribution}

Fig. 8 shows the geographic locations for stations in each cluster as determined by $K$-means and SOM clustering. The SOM clusters more evenly distribute stations among clusters and offer alternative interpretations for regionalization and possible influences of physiography on watershed characteristics. Both methods group Northern and Western stations in Cluster 3. Eastern watersheds are grouped in Clusters 1 and 2 although there is an overlap between methods and clusters within methods. This result suggests that natural flows can be expected to be more similar in Northern and Western areas with Eastern watersheds producing different flow conditions. This interpretation is consistent with the physiography in that Eastern watersheds are steeper and potentially more subject to direct typhoon effects. The Western water- sheds are in a coastal plain with Northern watersheds somewhat in the rain shadow of the central mountains.

The results of this geographic distribution considering TEIS statistics are informative. For the rate of change statistics, in both clustering methods Cluster 1 grouped stations with higher than average values, Cluster 2 grouped with stations near average values, and Cluster 3 grouped with stations with lower than average values. For other characteristics, there was more differences between $\mathrm{K}$ means and SOM clustering. For flow frequency statistics Cluster 1 had stations with higher values for both methods, Cluster 2 had stations with high values in $\mathrm{K}$-means and near average for the SOM method. Cluster 3 had below average values for both methods. For event frequency Clusters 1 and 2 in both methods grouped stations with lower than
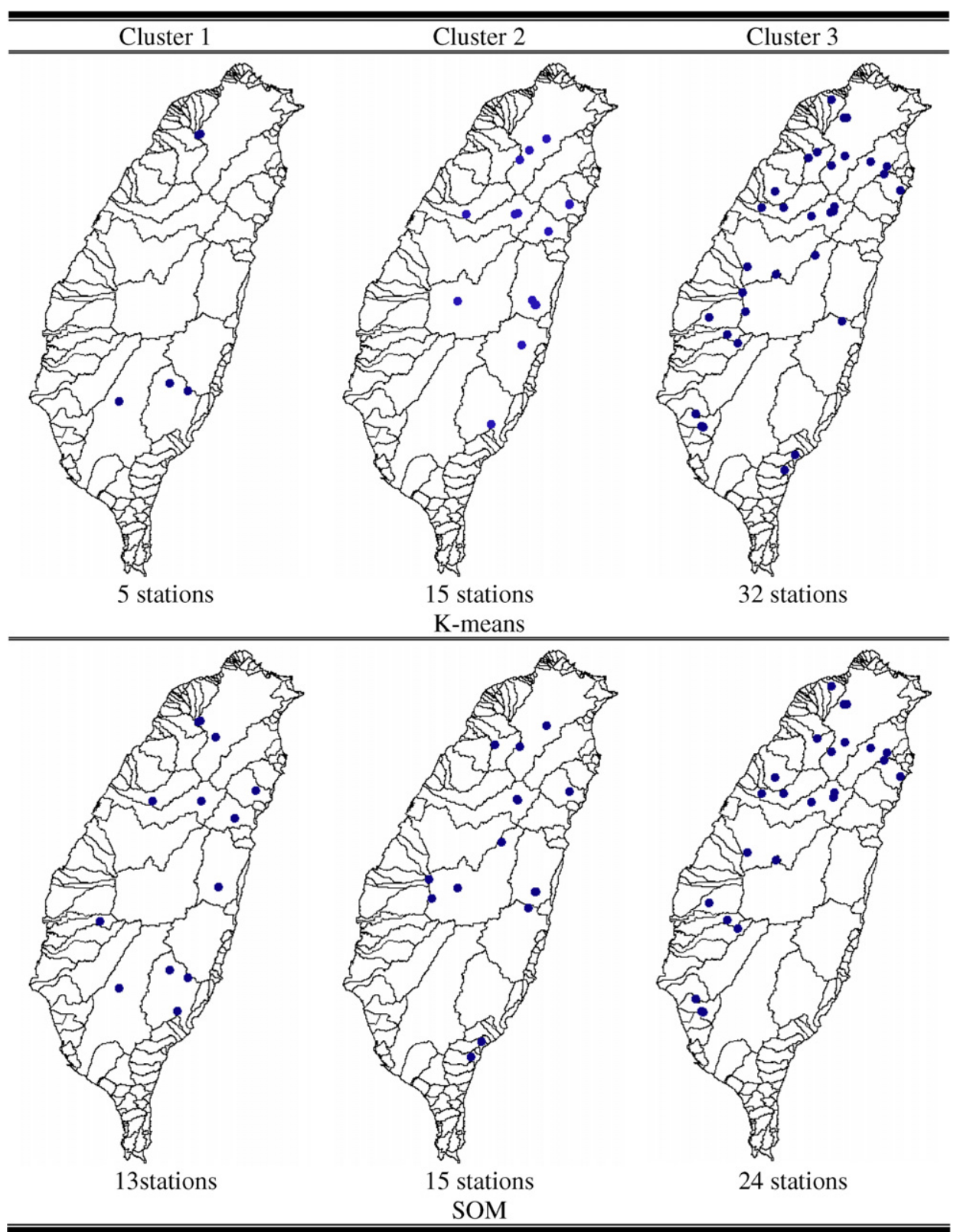

Figure 8 The geographic location of stations in K-means and SOM clusters. 
average values while Cluster 3 had near average values for $K$-means and higher than average station in SOM clustering. The clustering of stations for event duration was similar with Clusters 1 and 2 containing stations with averages below or near average and Cluster 3 containing stations with stations having higher than average values. The cluster groupings for both methods provide a means to further refine geographic differences in hydrologic statistics. These results suggest that independent of the number of stations in clusters produced by the two methods, clustering grouped stations based on TEIS statistics that have a consistent difference from island averages. When considering Oden and Poff's objective of discovery of multicollinearity, these analyses indicate that hydrologic statistics do differ in groups of watersheds and that the TEIS provides a set of hydrologic statistics that can be used by either K-means or SOM clustering to identify dominant patterns of flow that are important in ecohydrology.

\section{Correlation analysis}

Correlation analysis is regularly used in hydrology to relate similar variables in a dataset. Because a correlation coefficient indicates the strength of a linear relationship between two random variables, correlation has provided a basis for
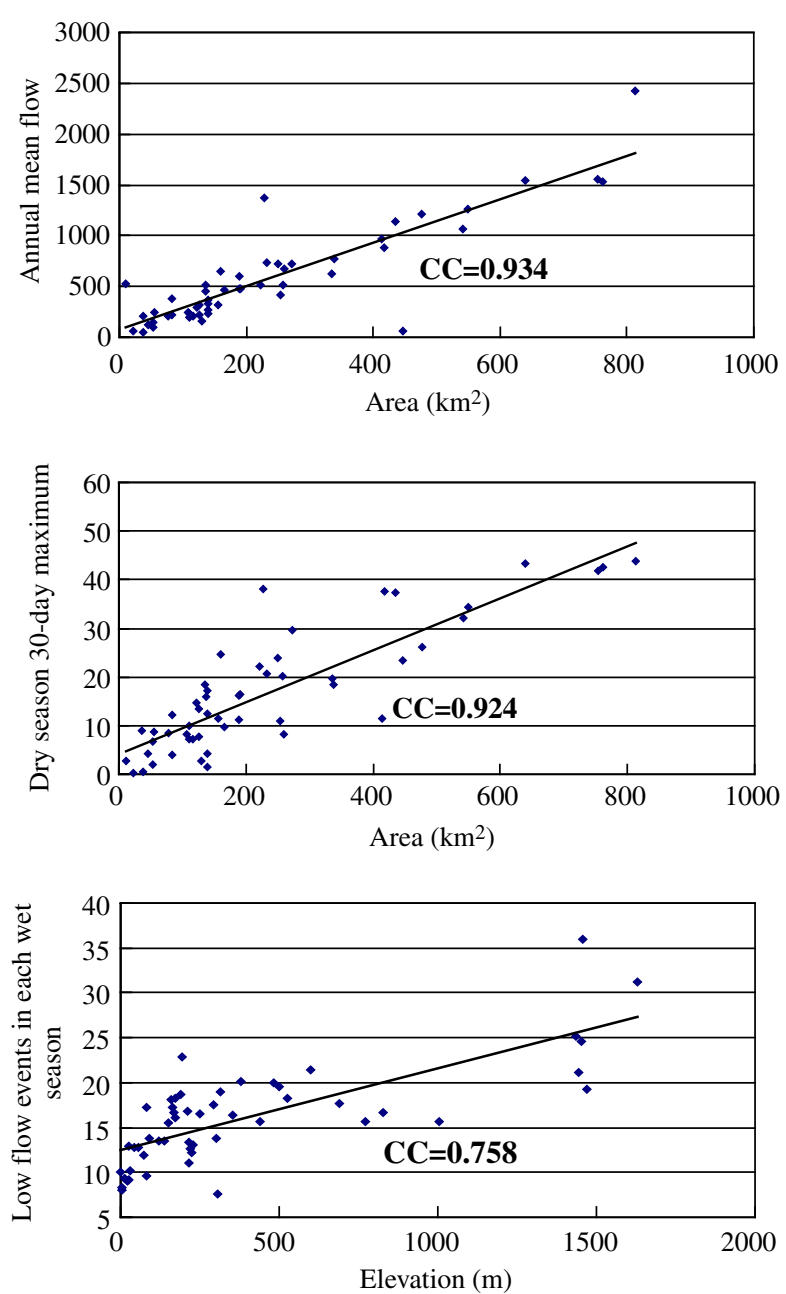

identifying strong relationships between descriptive variables. Correlation procedures were used in this analysis related TEIS statistics and the two physiographic variables measured for each station (area and elevation). The results indicate that the rate of change and flow frequency statistics were highly correlated with watershed area (Table 2). For example, the correlation between area and minimum flow was as high as 0.957 for the wet season 30-day minimum. Other correlations between watershed area and some groups of TEIS statistics are not strong. Event frequency and event duration have low, negative correlations with watershed area. This high, and then a lack of, correlation with TEIS statistics is a useful finding for ecohydrologic analysis. The correlation between flow volume statistics and area is expected and provides some utility in estimating natural flow characteristics based on watershed area for ungauged watersheds. The lack of correlation among area and event variables is also expected, because frequency statistics are driven by rainfall variability, which is not normalized by watershed area. The opposite results were observed for elevation. Low, negative correlations with elevation for flow volume statistics and moderate correlation was present in event statistics. This is also an expected result because elevation is related to smaller watershed area and watershed location and orientation which can be expected to
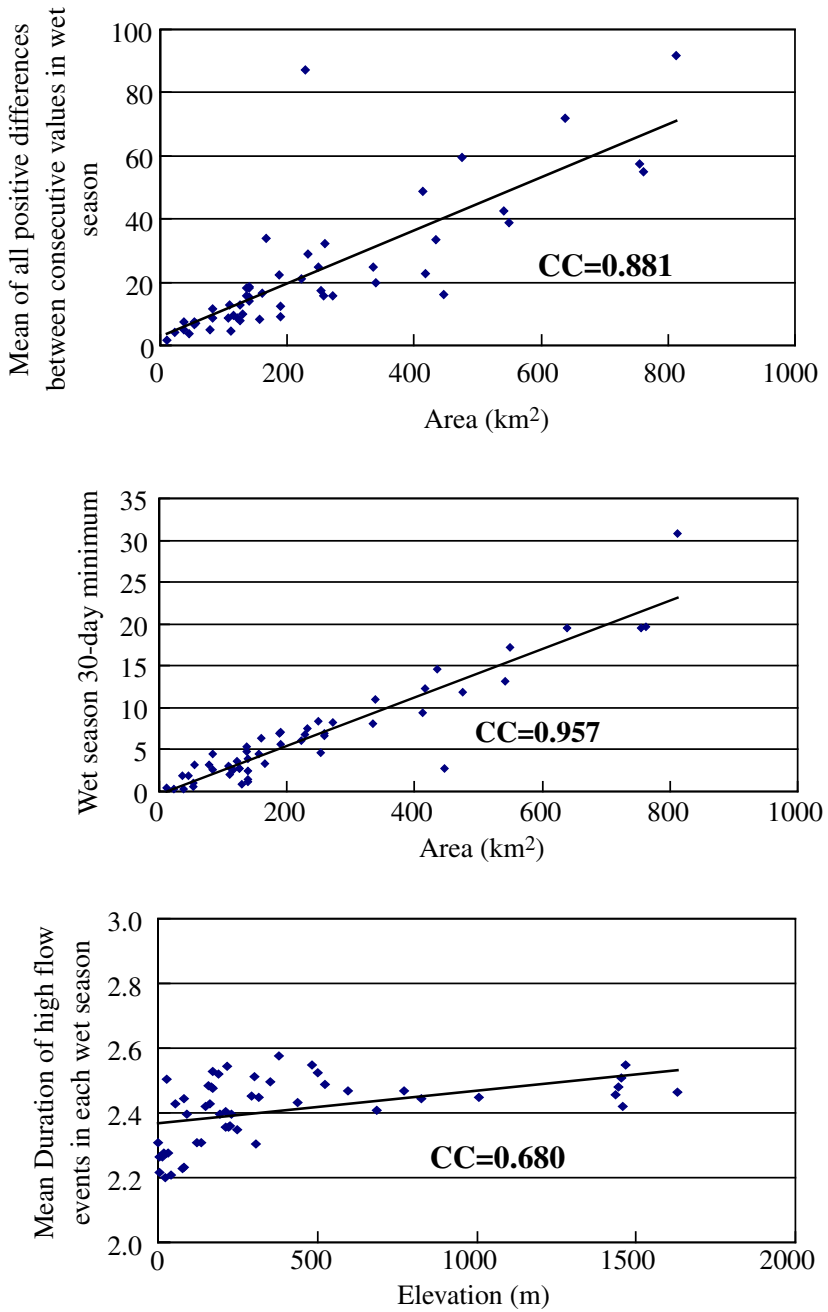

Figure 9 Correlation patterns. 
influence rainfall characteristics and corresponding event frequency and duration statistics. The lower correlation reflects not only elevation differences, but also unknown effects of elevation related to factors such as typhoon path, rain shadowing, or landscape features such as vegetation type and geological controls of geomorphology. Several correlation value plots are provided in Fig. 9.

\section{Redundancy}

The presentation of TEIS hydrologic statistics in Table 1 suggests a high level of information redundancy in these statistics as was found by Olden and Poff (2003). In an effort to identify a minimum set of statistics needed to describe the main aspects of flow regime, Olden and Poff (2003) used principal components analysis, while this analysis used clustering algorithms. Fig. 7 illustrates the redundancy in hydrologic statistics as determined by $K$-mean and SOM clustering where clusters contain TEIS statistics for flow, magnitude, frequency, and duration. It would be possible based only on these hydrologic statistics to select a small set of statistics for natural flow characterization. Although it is possible to identify the information redundancy for purely hydrologic statistics, the actual information redundancy in ecohydrology statistics is not the same. For example, redundancy in hydrologic statistics may be identified for 1-day, 3-day, and 10-day maxima, but these statistics from an ecohydrology perspective each provide information critical for certain species. For example, a species life history, behavior, or physiology determines the effect of flow regime change and 1-, 3-, or 10-day minimum or maximum flow conditions may result in suitable or unsuitable habitat for a target species. Our analysis shown Table 1 finds that the TEIS statistics provide a useful characterization of flow conditions that assist in determining how flow meets the needs of both target species and groups of species in communities of organisms. The TEIS provided a range of hydrologic statistics with high information redundancy for hydrologic description but non-redundant information that is useful for both the target species and the overall aquatic community management.

\section{Conclusions}

The objective of this research was to use selected hydrologic statistics in a comprehensive analysis of flow characteristics, information redundancy, and the use of hydrologic statistics in ecohydrology. The flow monitoring network in Taiwan provided a dense network of gauging stations where topography and climate are expected to play a major role in watershed hydrology. The Taiwan ecohydrologic indicator system (TEIS) (Suen, 2005) was used to select a group of hydrologic statistics and these statistics were calculated for 52 gauging stations located in relatively undisturbed watersheds. Because watersheds were relatively undisturbed, the hydrologic statistics are expected to identify the natural flow characteristics for Taiwan and to reveal how the TEIS statistics could be useful in ecohydrologic interpretations.

The TEIS statistics revealed seasonal differences in flow and helped characterize changes in consecutive values and flow frequency issues. The analysis identified that the dry season was characterized by consistent low flows with relatively small, but regular, changes in flow and expected habitat. In the wet season, low flows were similar to dry season values, but more frequent events, and events producing flows over 100 times low flow volumes could be expected. Flow in both dry and wet seasons had high numbers of flow reversals, approximately once every 4 days. This natural flow regime characterization for Taiwan is generally consistent with the qualitative assessments but TEIS statistics provide a detailed picture of natural flows that can be associated directly with the autecology of Taiwan's fisheries.

Further analysis applied clustering techniques to assess the existing regionalization procedures and to provide a sense of associations among watersheds. Three clusters of stations were identified with clusters defining groups of largely Western and Northern stations in the largest cluster, and central and Eastern stations in other clusters. The cluster analysis was useful in analyzing the structure of data resulting from calculating TEIS statistics. The cluster groupings did not have a strong connection to existing regional divisions that were based on purely management considerations. The $K$-means and SOM clustering methods did produce different cluster groupings with SOM clustering more evenly distributing stations among clusters. Comparing the results obtained by $\mathrm{K}$-means and SOM, the SOM clustering can group stations with less variability in each cluster and can clearly distinguish the difference between clusters. It appears that the SOM provides a better clustering for TEIS statistics.

Correlation analysis found a high correlation between watershed area and flow variables. Poor correlations were found between watershed area and frequency variables. The identified correlations suggest that it is possible to identify relationships between TEIS statistics and watershed area to help extrapolate the selected results to ungauged watersheds. For example, generally high correlations with flow volume statistics suggest that general assessments of flow related habitat conditions can be based on watershed area providing a means to develop flow management strategies from autecological relationships in ungauged watersheds in Taiwan. Low correlations of watershed area with event statistics suggest that when the analysis of life history or event related effects are needed, watershed area provides a poor means of addressing ecohydrology issues and secondary analysis is required.

An assessment of information redundancy found that if the objective was simply historic natural flow characterization, there was a high level of information redundancy in the TEIS indicators. If the objective was ecohydrologic characterization of natural flows, the TEIS provided the needed statistics to better relate autecological needs of both target species and aquatic communities. The TEIS statistics provide insight into the natural flow variability that supports populations of native fish. The contrasting conditions between wet and dry seasons drive a life history of native species and provide the opportunity for the management of flows to produce habitat conditions which are not advantageous to exotic species by duplicating a natural flow regime that has a high frequency of flow reversals in both wet and dry seasons. 


\section{Acknowledgements}

This study is funded by the Water Resources Planning Institute, Water Resource Agency, MOEA, Taiwan, ROC. The Water Resources Agency also provided gauging data used in these analyses. In addition, the authors are indebted to the reviewers for their valuable comments and suggestions.

\section{References}

Allan, J.D., 2004. Landscape and riverscapes: the influence of land use on river ecosystems. Annual Reviews of Ecology, Evolution and Systematics 35, 257-284.

Chang, F.J., Herricks, E.E., 2005. Integration of ecohydrology in managing water resources. Water Resources Planning Institute Technical Report (ISBN 986-00-3534-3), Water Resources Agency of MOEA, Taiwan.

Chang, F.J., Chang, L.C., Wang, Y.S., 2007. Enforced self-organizing map neural networks for river flood forecasting. Hydrological Processes 21, 741-749.

Chow, V.T., Maidment, D.R., Mays, L.W., 1988. Applied Hydrology. McGraw-Hill, New York.

Clausen, B., Biggs, B.J.F., 2000. Flow variables for ecological studies in temperate streams: groupings based on covariance. Journal of Hydrology 237 (3-4), 184-197.

Cushman, R.M., 1985. Review of ecological effects of rapidly varying flows downstream from hydroelectric facilities. North American Journal of Fisheries Management 5, 330-339.

Gordon, N.D., McMahon, T.A., Finlayson, B.L., Gippel, C.J., Nathan, R.J., 2004. Stream Hydrology - An Introduction for Ecologists. John Wiley and Sons, New York.

Harvey, B.C., 1987. Susceptibility of young-of-the-year fishes to downstream displacement by flooding. Transactions of the American Fisheries Society 116 (6), 851-855.

Herricks, E.E., 1996. Water quality issues in river channel restoration. In: Brookes, A.W., Shields, D.J. (Eds.), River Channel Restoration. John Wiley and Sons, New York, pp. 179-200.

Herricks, E.E., Suen, J.P., 2006. Integrative analysis of water quality and physical habitat in the ecological design of water resources projects. Journal of Environmental Science and Health, Part A 41, 1303-1314.

Hughes, D.A., Hannart, P., 2003. A desktop model used to provide an initial estimate of the ecological instream flow requirements of rivers in South Africa. Journal of Hydrology 270, 167-181.

Hughes, J.M.R., James, B., 1989. A hydrological regionalization of streams in Victoria, Australia, with implications for stream ecology. Australian Journal of Marine and Freshwater Research 40 (3), 303-326.

Karr, J.R., 1981. Assessment of biotic integrity using fish communities. Fisheries 6, 21-27.

Kohonen, T., 1982. Self-organized formation of topologically correct feature maps. Biological Cybernetics 43, 59-69.
Landres, P.B., Morgan, P., Swanson, F.J., 1999. Overview of the use of natural variability concepts in managing ecological systems. Ecological Applications 9, 1179-1188.

Magoulick, D.D., Kobza, R.M., 2003. The role of refugia for fishes during drought: a review and synthesis. Freshwater biology 48 (7), 1186-1198.

Naesje, T., Jonsson, B., Skurdal, J., 1995. Spring flood: a primary cue for hatching of river spawning Coregoninae. Canadian Journal of Fisheries and Aquatic Sciences 52 (10), 2190-2196.

Nesler, T.P., Muth, R.T., Wasowicz, A.F., 1988. Evidence for baseline flow spikes as spawning cues for Colorado Squawfish in the Yamoa River, Colorado. American Fisheries Society Symposium 5, 68-79.

Olden, J.D., Poff, N.L., 2003. Redundancy and the choice of hydrologic indices for characterizing streamflow regimes. River Research and Applications 19, 101-121.

Poff, N.L., 1996. A hydrogeography of unregulated streams in the United States and an examination of scale-dependence in some hydrological descriptors. Freshwater Biology 36 (1), 71-91.

Poff, N.L., Allan, J.D., Bain, M.B., Karr, J.R., Prestegaard, K.L., Richter, B.D., Sparks, R.E., Stromberg, J.C., 1997. The natural flow regime. Bioscience 47 (11), 769-784.

Richter, B.D., Baumgartner, J.V., Powell, J., Braun, D.P., 1996. A method for assessing hydrologic alteration within ecosystems. Conservation Biology 10 (4), 1163-1174.

Richter, B.D., Baumgartner, J.V., Wigington, R., Braun, D.P., 1997. How much water does a river need? Freshwater Biology 37 (1) 231-249.

Richter, B.D., Mathews, R., Harrison, D.L., Wigington, R., 2003. Ecologically sustainable water management: managing river flows for ecological integrity. Ecological Applications 13 (1), 206-224.

Sharma, S., 1996. Applied Multivariate Techniques. John Wiley \& Sons Inc., New York, NY, USA.

Suen, J.P., 2005. Ecologically based methods for multi-objective water resources management in Taiwan. Ph.D. Dissertation, University of Illinois at Urbana-Champaign, Urbana, USA.

Suen, J.P., Herricks, E.E., 2006. Investigating the causes of fish community change in the Dahan River (Taiwan) using an autecology matrix. Hydrobiologia.

Tew, K.S., Han, C.C., Chou, W.R., Fang, L.S., 2002. Habitat and fish fauna structure in a subtropical mountain stream in Taiwan before and after a catastrophic typhoon. Environmental Biology of Fishes 65 (4), 457-462.

Ward, J.V., Stanford, J.A., 1983. The intermediate-disturbance hypothesis: an explanation for biotic diversity patterns in lotic ecosystems. In: Fontaine, T.D., IIIIII, Bartell, S.M. (Eds.), Dynamics of Lotic Ecosystems. Ann Arbor Science, Ann Arbor, MI.

Ward, J.V., Tockner, K., Schiemer, F., 1999. Biodiversity of floodplain river ecosystems: ecotones and connectivity. Regulated Rivers-Research \& Management 15 (1-3), 125-139.

Welcomme, R.L., 1985. River Fisheries. FAO Fisheries Technical Paper, 262. Food and Agriculture Organization of the United Nations, Rome. 